\title{
openheart Two-year outcome after early or late Intervention in non-ST elevation acute coronary syndrome
}

\author{
Erik A Badings, ${ }^{1}$ Wouter S Remkes, ${ }^{2}$ Salem H K The, ${ }^{3}$ Jan-Henk E Dambrink, ${ }^{2}$ \\ Geert Tjeerdsma, ${ }^{4}$ Saman Rasoul, ${ }^{5,6}$ Jorik R Timmer, ${ }^{2}$ Marloes L J van der Wielen, ${ }^{3}$ \\ Dirk J A Lok, ${ }^{1}$ Renicus S Hermanides, ${ }^{2}$ Jan Van Wijngaarden, ${ }^{1}$ \\ Harry Suryapranata, ${ }^{2,7}$ Arnoud W J van 't Hof ${ }^{2}$
}

To cite: Badings EA, Remkes WS, The SHK, et al. Twoyear outcome after early or late Intervention in non-ST elevation acute coronary syndrome. Open Heart 2017;4:e000538. doi:10.1136/ openhrt-2016-000538

Received 14 September 2016 Revised 5 December 2016 Accepted 10 January 2017

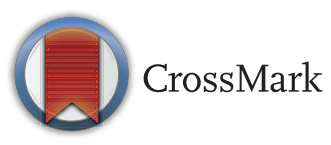

'Department of Cardiology, Deventer Ziekenhuis, Deventer, Netherlands

2Department of Cardiology, Isala klinieken, Zwolle, Netherlands ${ }^{3}$ Department of Cardiology, Treant Zorggroep locatie ziekenhuis Bethesda, Hoogeveen, Netherlands ${ }^{4}$ Department of Cardiology, Ziekenhuis De Tjongerschans, Heerenveen, Netherlands ${ }^{5}$ Department of Cardiology, Maastricht UMC, Maastricht Netherlands

${ }^{6}$ Department of Cardiology, Atrium Medisch Centrum, Heerlen, Netherlands ${ }^{7}$ Department of Cardiology, Radboudumc, Nijmegen, Netherlands

Correspondence to Dr Arnoud WJ van 't Hof, Isala Klinieken, Department of Cardiology, Dokter van Heesweg 28025 AB Zwolle, The Netherlands; a.w.j.vant.hof@ isala.nl

\section{ABSTRACT}

Objective To compare long-term outcome of an early to a delayed invasive strategy in high-risk patients with non-ST elevation acute coronary syndrome (NSTE-ACS).

Methods This prospective, multicentre trial included patients with NSTE-ACS and at least two out of three of the following high-risk criteria: (1) evidence of extensive myocardial ischaemia on ECG, (2) elevated biomarkers for myocardial necrosis and (3) age above 65 years. Patients were randomised to either an early (angiography and revascularisation if appropriate $<12$ hours) or a delayed invasive strategy ( $>48$ hours after randomisation). Endpoint for this prespecified long-term follow-up was the composite incidence of death or reinfarction after 2 years. Data collection was performed by telephone contact with the patients, their relatives or general practitioner and by review of hospital records.

Results Endpoint status after 2-year follow-up was collected in 521 of 542 initially enrolled patients. Incidence of death or reinfarction was $11.8 \%$ in the early and $13.1 \%$ in the delayed treatment group (relative risk $(\mathrm{RR})=0.90$, $95 \% \mathrm{Cl} 0.57$ to 1.42). No significant differences were found in occurrence of the individual components of the primary endpoint: death $6.1 \%$ vs $8.9 \%$, RR 0.69 ( $95 \% \mathrm{Cl} 0.37$ to 1.27 ), reinfarction $6.5 \%$ vs $5.4 \%$, RR 1.20 (95\% Cl 0.60 to 2.38). Post-hoc subgroup analysis showed statistical significant interaction between age and treatment strategy on outcome $(\mathrm{p}=0.02)$.

Conclusions After 2 years follow-up, no difference in incidence of death or reinfarction was seen between early to late invasive strategy. These findings are in line with results of other studies with longer follow-up. Older patients seem to benefit more from early invasive treatment.

\section{INTRODUCTION}

Although numerous trials have investigated the outcome of an early versus a delayed invasive treatment strategy in patients with non-ST elevation acute coronary syndrome (NSTE-ACS), controversy remains about the optimal timing of angiography and revascularisation in this patient group. Several meta-analyses ${ }^{1-5}$ pooled the results of these trials to systematically address this question.

\section{KEY QUESTIONS}

What is already known about this subject?

- Early intervention in patients with non-ST elevation acute coronary syndrome (NSTE-ACS) results in a reduction of the incidence of recurrent ischaemia and duration of hospital stay but not in mortality or reinfarction after one or several months. Little is known of the effect on clinical endpoints after longer follow-up.

What does this study add?

- This prespecified analysis of the ELISA-3 trial (trial registration number ISRCTN39230163) after 2-year follow-up showed no difference in incidence of death or reinfarction between early to late invasive strategy. Exploratory subgroup analysis showed that very elderly patients seem to benefit more from early invasive treatment.

How might this impact on clinical practice?

- Considering comparable clinical outcome after short-term and long-term follow-up, no adjustment of the current non-ST-Segment elevation myocardial infarction guideline is necessary in timing of intervention in patients with NSTE-ACS. In daily practice, older patients often undergo angiography relatively late after admission. Our long-term trial results suggest that older age patients should rather be considered for early angiography, but this needs further investigation.

The main conclusion is that early intervention results in a reduction of the incidence of recurrent ischaemia and duration of hospital stay but not in mortality or reinfarction. Based on these results, current guidelines recommend intervention within 24 hours in NSTE-ACS patients with one or more highrisk criteria.

Follow-up in the majority of the above-mentioned trials has been limited to one to several months. However, long-term clinical outcome is essential to decide about the optimal timelines of intervention in these 
patients. In this publication we present the results of the prespecified analysis after 2-year follow-up of the ELISA-3 trial, an investigator initiated a randomised, open, multicentre study comparing early versus late angiography and revascularisation in high-risk patients with NSTE-ACS.

\section{METHODS}

The design and the results at 30-day follow-up of the ELISA-3 trial have been published previously. ${ }^{7}$ In short, patients were eligible if they were hospitalised with ischaemic chest pain or dyspnoea at rest and had at least 2 out of 3 of the following high-risk characteristics: (1) evidence of extensive myocardial ischaemia on ECG (shown by new cumulative ST depression $>5 \mathrm{~mm}$ or temporary ST segment elevation in two contiguous leads $<30 \mathrm{~min}$ ), (2) elevated biomarkers (troponin $\mathrm{T}>0.10 \mu \mathrm{g} / \mathrm{L}$ or myoglobin $>150 \mu \mathrm{g} / \mathrm{L}$ ) or elevated creatine kinase-myocardial band (CKMB) fraction ( $>6 \%$ of total creatine kinase $(\mathrm{CK})$ ) and (3) age above 65 years. Randomisation had to take place within 24 hours of the last episode of ischaemic symptoms. Exclusion criteria were persistent ST segment elevation, symptoms of ongoing myocardial ischaemia despite optimal medical therapy, contraindication for diagnostic angiography, active bleeding, cardiogenic shock, acute posterior infarction and life expectancy less than 1 year. Patients were 1:1 randomly assigned by a web-based randomisation system to an early treatment strategy (angiography and subsequent revascularisation as soon as possible but within 12 hours of randomisation) or a delayed treatment strategy (no sooner than 48 hours after randomisation). The primary endpoint was the combined incidence of death, reinfarction and/or recurrent ischaemia at 30-day follow-up. Follow-up for 2 years after the index event for incidence of mortality or reinfarction was pre-specified in the protocol. Patients were contacted by telephone to collect information about vital status and potential endpoints. If patients could not be contacted by telephone, their relatives or general practitioner was contacted to obtain information. In case of re-hospitalisation, hospital records were reviewed.

Data were analysed according to the intention to treat principle. Continuous variables were expressed as median and first and third quartiles, and were compared between the intervention groups using a Mann-Whitney $\mathrm{U}$ test. Categorical data were described by proportions and compared with the ${ }^{2}$ test or Fisher exact test. Logistic regression was used to calculate the p-value of the interaction between the effect of the intervention and the subgroups on the primary endpoint. All tests were two sided, and an alpha of 5\% was used. Statistical analysis was performed with SPSS (V.20). Cumulative event rates were estimated with the Kaplan-Meier method and compared with log-rank test.

The study complied with the Declaration of Helsinki, was approved by the ethics committee of the Isala Klinieken, Zwolle, The Netherlands, and was registered in the ISRCTN Register (ISRCTN39230163). More information about this trial can be found on the website http:/ /www.isrctn.com

\section{RESULTS}

Between July 2007 and June 2012, 542 patients were included in six Dutch hospitals of which one had 24 hours facilities for (primary) percutaneous coronary intervention (PCI) and coronary arterial bypass graft. Eight patients were excluded. Two hundred and sixtynine patients were randomised to early invasive strategy and 265 to delayed invasive strategy (figure 1). Baseline characteristics were well balanced between the groups (table 1).

Median time from admission to randomisation was 2.0 hours in the immediate group and 2.1 hours in the delayed treatment group $(\mathrm{p}=0.97)$; median interval between randomisation and angiography was 2.6 hours and 54.9 hours, respectively $(\mathrm{p}<0.001)$. Pharmacological therapy after 30 days and one- and two-year follow-up is shown in table 2 and was comparable between both treatment groups. The use of medication for secondary prevention was high; almost all patients not treated with oral anticoagulants used aspirin, and over $80 \%$ used beta blockers and statins.

The original publication of the ELISA-3 trial showed a non-significant reduction of $30 \%$ in the early invasive treated patients on the primary composite endpoint of death, reinfarction or recurrent ischaemia after 30-day follow-up. ${ }^{7}$ Median duration of hospitalisation in this group was statistically significant shorter (4 days, vs 6 days in the late treatment group). Two-years follow-up could be performed in 521 patients, $96 \%$ of the initially enrolled patients. The cumulative incidence of death or reinfarction after 2-years follow-up did not differ significantly (figure 2; log rank test $\mathrm{p}=0.67$ ). This combined endpoint occurred in $11.8 \%$ of patients in the the early invasive group and $13.1 \%$ in the delayed treatment group (relative risk $(\mathrm{RR})=0.90,95 \% \mathrm{CI} 0.57$ to 1.42 , table 3 ). No significant differences were found in the occurrence of the individual components of the primary endpoint: the rate of death $(6.1 \%$ vs $8.9 \%$, RR $0.69,95 \%$ CI 0.37 to $1.27)$ and recurrent myocardial infarction $(6.5 \%$ vs $5.4 \%$, RR $1.20,95 \%$ CI 0.60 to 2.38 ).

Results of prespecified and post-hoc subgroup analysis are shown in figures 3 and 4, respectively. Only statistical significant interaction was found between age group (above vs below median age of 71.9 years) and treatment strategy on outcome $(\mathrm{p}=0.022)$. In the $50 \%$ oldest patients, the combined endpoint occurred in $13.6 \%$ of patients in the early intervention as compared with $21.7 \%$ of those in the delayed intervention group. For the patients aged under 71.9 years, the combined endpoint occurred in $10 \%$ and $4.6 \%$, respectively.

\section{DISCUSSION}

These long-term follow-up results of the ELISA-3 trial show that in high-risk patients with NSTE-ACS, early angiography and revascularisation (median 2.6hours 


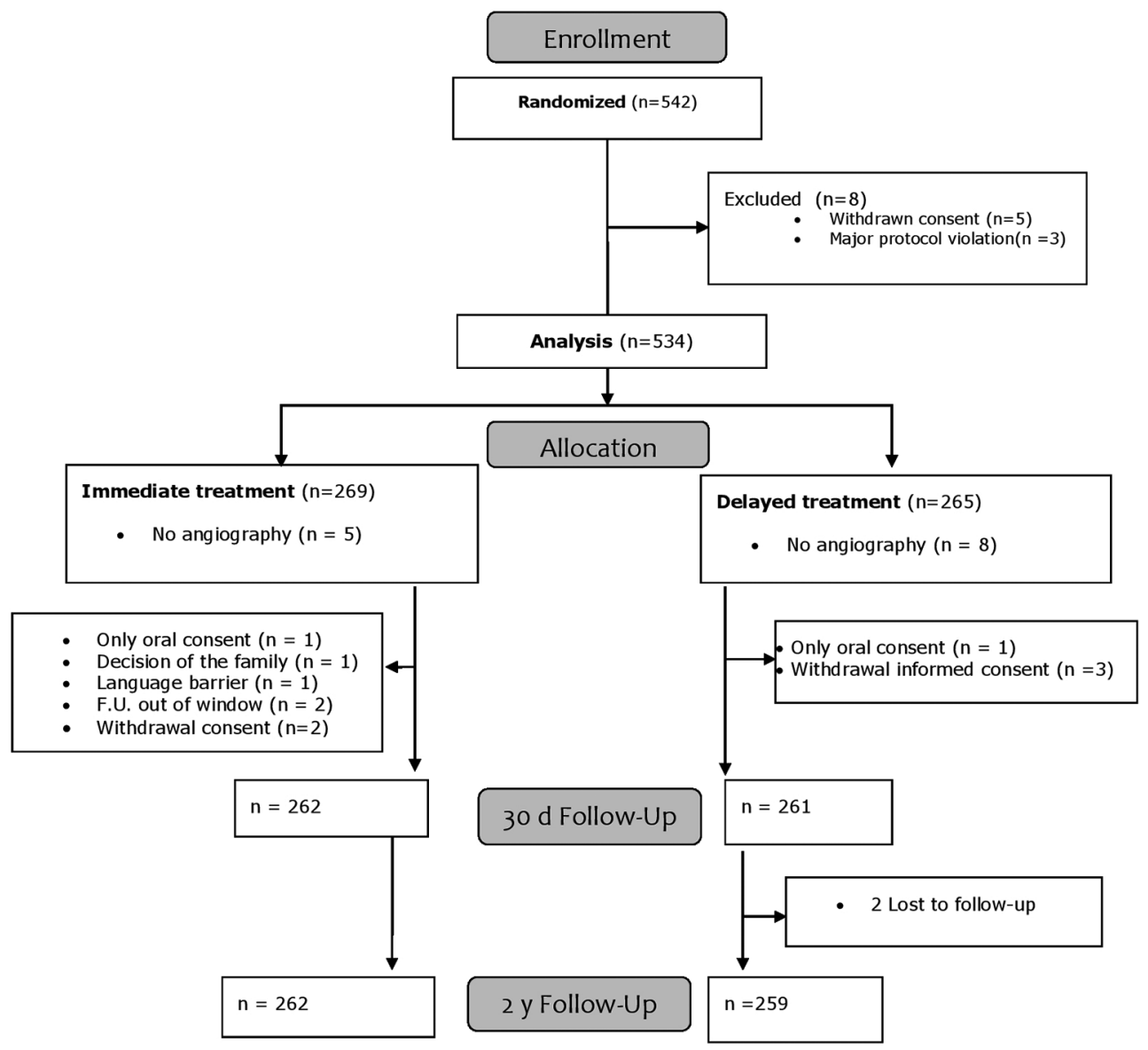

Figure 1 Trial flow chart.

\section{Table 1 Patient baseline characteristics}

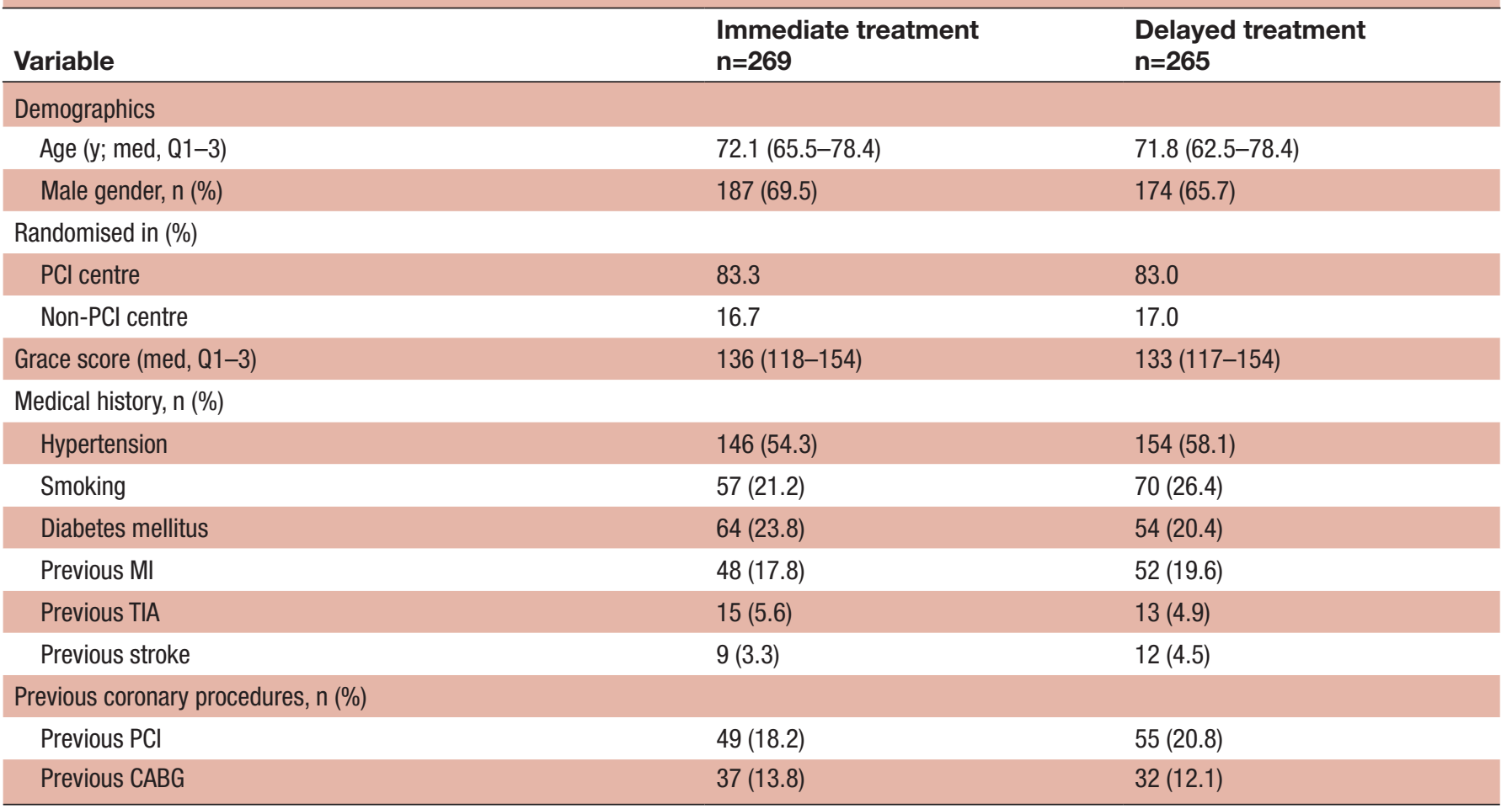

CABG, coronary arterial bypass graft; med, median; MI, myocardial infarction; PCl, percutaneous coronary intervention; Q1-3, 1st and 3rd quartile; TIA, transient ischaemic attack; y, years. 
Table 2 Medication therapy after 30 days, 1- and 2-year follow-up in early and late intervention group

\begin{tabular}{|c|c|c|c|c|c|c|}
\hline & 30 days & & 1 year & & 2 years & \\
\hline & $\begin{array}{l}\text { Early } \\
n=262(\%)\end{array}$ & $\begin{array}{l}\text { Late } \\
n=261(\%)\end{array}$ & $\begin{array}{l}\text { Early } \\
n=262(\%)\end{array}$ & $\begin{array}{l}\text { Late } \\
\mathrm{n}=259(\%)\end{array}$ & $\begin{array}{l}\text { Early } \\
n=262(\%)\end{array}$ & $\begin{array}{l}\text { Late } \\
\mathrm{n}=259(\%)\end{array}$ \\
\hline Aspirin & 84.0 & 84.8 & 79.4 & 80.0 & 78.8 & 75.1 \\
\hline Clopidogrel & 67.2 & 64.6 & 42.6 & 46.7 & 11.0 & 10.5 \\
\hline Anticoagulance & 14.4 & 15.2 & 20.1 & 14.6 & 19.2 & 18.6 \\
\hline Beta blocker & 91.2 & 91.8 & 83.5 & 87.1 & 81.2 & 83.1 \\
\hline ACE inhibitors & 62.0 & 56.8 & 62.7 & 50.8 & 55.5 & 49.4 \\
\hline All-receptor blocker & 12.4 & 11.5 & 18.5 & 18.8 & 19.6 & 19.0 \\
\hline Statin & 90.0 & 88.1 & 87.6 & 85.8 & 85.3 & 81.9 \\
\hline Calcium blocker & 20.4 & 22.6 & 24.1 & 26.3 & 25.7 & 25.7 \\
\hline Nitrate & 14.1 & 17.3 & 18.1 & 20.8 & 18.4 & 16.9 \\
\hline
\end{tabular}

after admission) is not better than intervention 48 hours or more after admission in terms of mortality or reinfarction after a 2-year follow-up. Considering the results after 30-day follow-up, in which we found a non-significant reduction of $30 \%(\mathrm{p}=0.135)$ on the combined endpoint of mortality, reinfarction or recurrent ischaemia, effects of timing of intervention on short-term and long-term clinical outcome are comparable.

Only a few other studies described the long-term effects of timing of intervention in patients with NSTE-ACS. The SICCA trial, ${ }^{8}$ comparing early versus delayed invasive strategy in high-risk NSTE-ACS patients reported only mortality after 4 years as secondary endpoint, which was equal in both treatment arms. The OPTIMA trial ${ }^{9}$

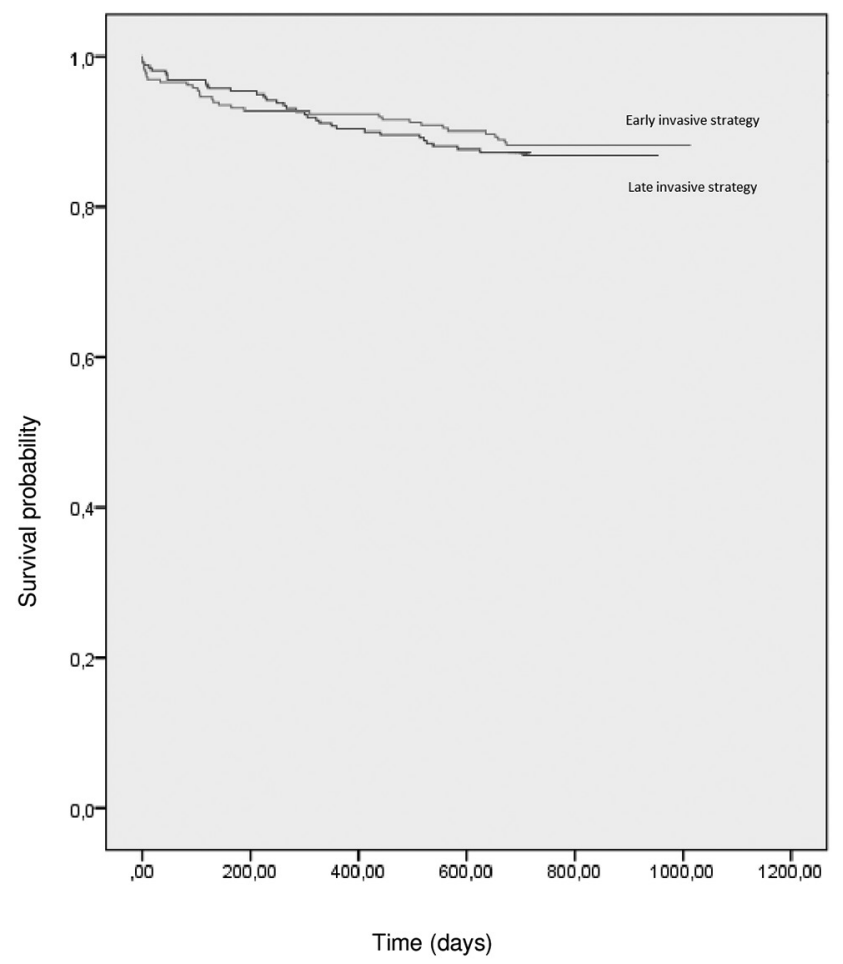

Figure 2 Kaplan-Meier curve for event free survival of primary endpoint. recently reported 5-year outcome in NSTE-ACS patients after immediate versus deferred PCI and found no differences in the primary composite endpoint of death and spontaneous myocardial infarction (MI) but an increased risk of late spontaneous MI for patients treated with immediate PCI. We could not confirm this finding, but the studies are difficult to compare because of difference in patient population due to the fact that in the OPTIMA trial, patients were only randomised after coronary angiography, excluding patients not feasible for PCI or without significant coronary stenosis. Potential mechanisms of excess of MI in the immediate PCI group could be an increased risk of malpositioning and improper stent sizing or stenting of non-significant lesions due to overestimating of lesion severity in the acute setting.

One publication reported long-term outcome after early or delayed angiography in patients with NSTE-ACS undergoing a routine invasive management. ${ }^{10}$ In this post-hoc collaborative analysis of individual patient data from three trials comparing routinely versus selective invasive strategy, relationship between timing and outcome of patients originally randomised to the routine invasive arm of the trials was investigated. No difference in incidence of cardiovascular mortality or myocardial infarction after 5-year follow-up was found between early (within 2 days) or delayed (within 3-5 days) angiography in the routinely invasive treatment arm. Because timing of intervention was not randomised, these results might have been biased by unequal distribution of prognostic factors associated with timing of angiography. Also, the timing of the early angiography group in this study was comparable with that of the late treatment strategy of the ELISA-3 trial.

Although methodological differences between studies are hampering the interpretation of results, overall these findings are in line with our results, showing no clear benefit of early invasive treatment strategy in terms of mortality or re-infarction in short and longer term. This is confirmed by all published meta-analyses on this topic ${ }^{1-5}$ showing that early intervention-despite the large number of patients included-only results in 
Interventional cardiology

Table 3 Study endpoints after 30-day and 2-year follow-ups

\begin{tabular}{|c|c|c|c|c|}
\hline Variable & $\begin{array}{l}\text { Immediate } \\
\text { treatment }\end{array}$ & $\begin{array}{l}\text { Delayed } \\
\text { treatment }\end{array}$ & RR $(95 \%$ Cl) & $\begin{array}{l}\mathrm{p} \\
\text { Value }\end{array}$ \\
\hline 30-day follow-up & $n=262(\%)$ & $n=261(\%)$ & & \\
\hline Combined incidence of death, reinfarction and recurrent ischaemia & 9.9 & 14.2 & 0.70 (0.43 to 1.12$)$ & 0.14 \\
\hline Death & 1.1 & 1.1 & $1.00(0.20$ to 4.89$)$ & $>0.99$ \\
\hline Reinfarction & 1.9 & 0.8 & 2.49 (0.49 to 12.72$)$ & 0.45 \\
\hline Recurrent ischaemia & 7.6 & 12.6 & $0.60(0.36$ to 1.02$)$ & 0.06 \\
\hline 2-year follow-up & $\mathrm{n}=262(\%)$ & $\mathrm{n}=259(\%)$ & & \\
\hline Combined incidence of death or reinfarction & 11.8 & 13.1 & 0.90 (0.57 to 1.42$)$ & 0.66 \\
\hline Death & 6.1 & 8.9 & $0.69(0.37$ to 1.27$)$ & 0.23 \\
\hline Reinfarction & 6.5 & 5.4 & 1.20 (0.60 to 2.38$)$ & 0.60 \\
\hline
\end{tabular}

$\mathrm{RR}$, relative risk.

a statistically significant reduction of the incidence of recurrent ischaemia and duration of hospital stay, but not in mortality or re-infarction. Therefore, the basis of the I-A indication for early invasive strategy $(<24$ hours $)$ for NSTE-ACS patients with at least one high-risk criterion in the guidelines of the European Society of Cardiology for management of NSTE-ACS ${ }^{6}$ is somewhat questionable and puts a heavy burden on the capacity of cardiac catheterisation facilities.

\section{Subgroup analysis}

Of all trials comparing early versus later intervention in NSTE-ACS, the ELISA-3 included the oldest patient population with a median age of 72 years. We found a significant interaction between the age and treatment strategy and on the primary endpoint (figure 4). This means that in this relatively old population, in the oldest half aged over 72 years, the benefit of early intervention was more pronounced than in the youngest half. Other trials comparing early versus delayed intervention that performed subgroup analysis did not find this interaction with age. ${ }^{11-14}$ Although results of subgroup analysis should always be taken with caution, this finding is relevant because in clinical practice, elderly patients with NSTE-ACS less often receive aggressive invasive care treatment due to fear for complications with catheterisation and revascularisation procedures. ${ }^{15}{ }^{16}$ Despite more comorbidities, polypharmacy and physical frailty in this group of patients, a routine invasive treatment has shown to be superior over a selective invasive strategy ${ }^{16-18}$ Future studies or meta-analysis of data in elderly patients are needed to investigate the value of early angiography and revascularisation, if indicated.

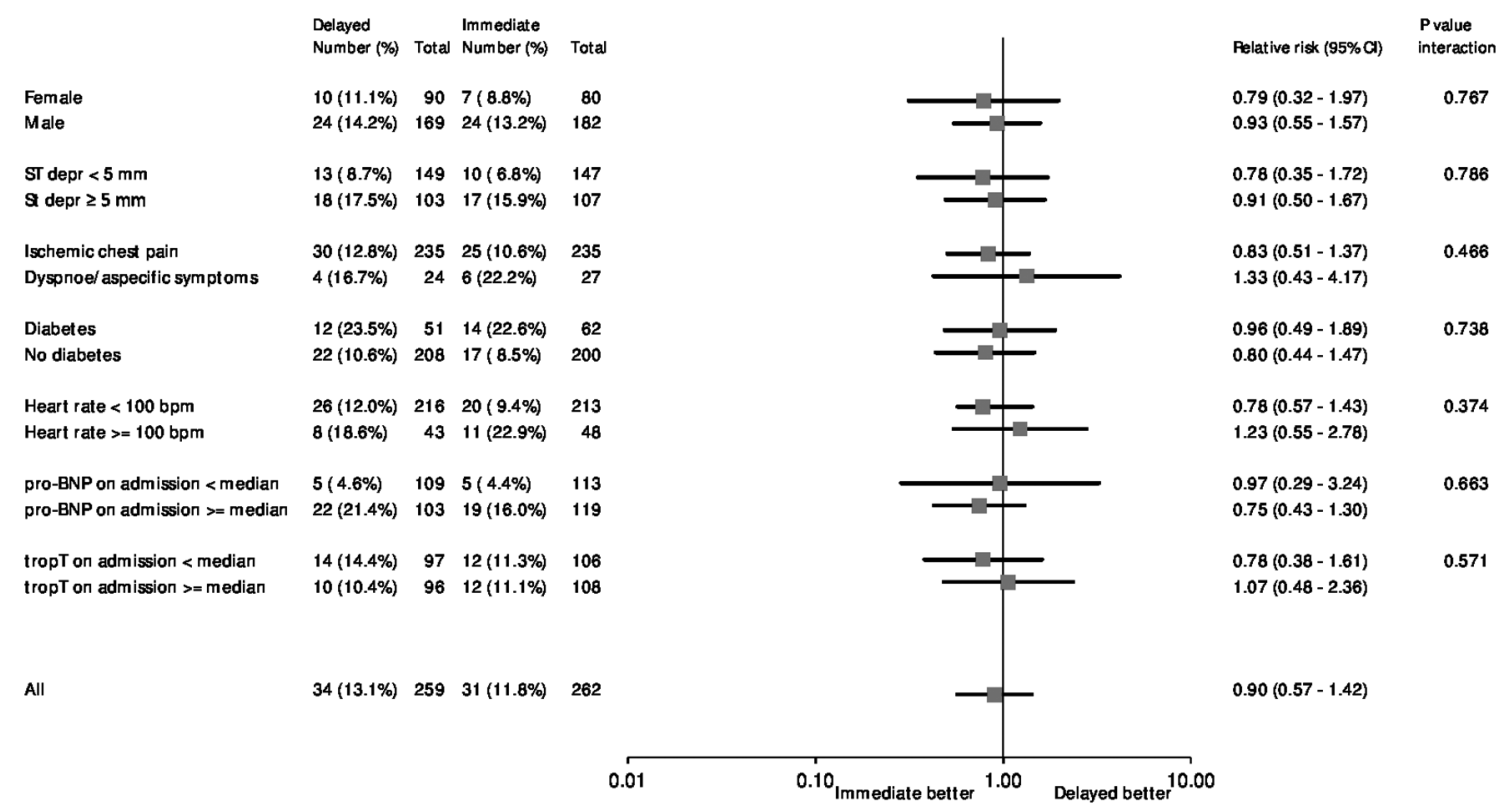

Figure 3 Forest plot of relative risk of primary endpoint at 2 years in pre-specified patient subgroups. Data are number or number (\%), unless otherwise indicated. Percentages are number of events divided by number of patients. Squares and horizontal bars represent within-subgroup relative risk and $95 \% \mathrm{Cls}$, respectively, on a log scale. Median pro-BNP=659 pg/mL. Median TropT=0.30 ng $/ \mathrm{mL}$. 


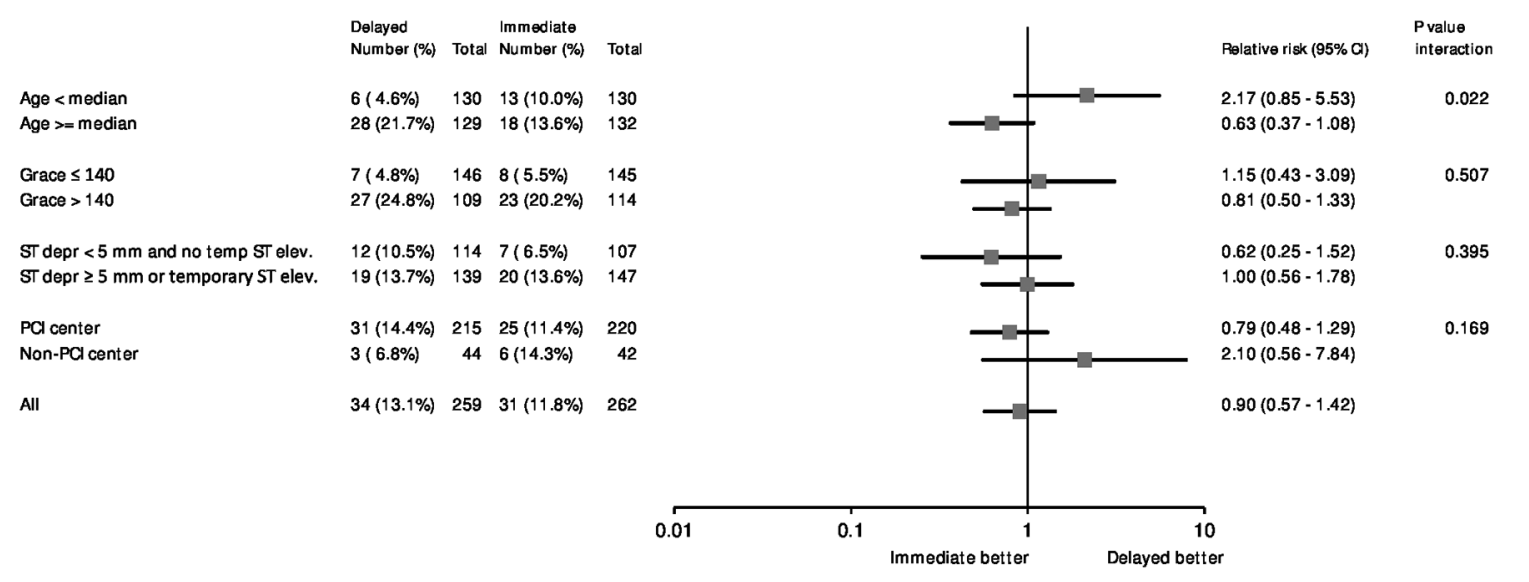

Figure 4 Forest plot of relative risk of primary endpoint at 2 year in ad hoc selected patient subgroups. Data are number or number (\%), unless otherwise indicated. Percentages are number of events divided by number of patients. Squares and horizontal bars represent within-subgroup relative risk and $95 \% \mathrm{Cls}$, respectively, on a log scale. Median age=71.9 years.

\section{Limitations}

Our study has some limitations. The study was not powered to detect a difference in death or MI at 2-year follow-up. Furthermore, the data for the 2-year follow-up were collected by contacting patients or their general practitioner by telephone and review of hospital records in case of rehospitalisation. This might have led to under-reporting of endpoints. Also, two patients were lost to follow up. Furthermore, the guidelines for treatment of patients with NSTE-ACS have changed since this trial that was performed between 2007 and 2012. For example, we did not use high-sensitive troponin assays, and patients were treated with clopidogrel instead of ticagrelor, which is now standard of care. This might influence the external validity of our results. Therefore, a new, adequately powered trial using contemporary diagnostic and therapeutic strategies on this topic is needed.

In conclusion, in patients with high-risk NSTE-ACS, we found that an immediate invasive strategy is not superior to a delayed invasive strategy in terms of incidence of the composite endpoint of death or reinfarction at 2-year follow-up. However, shorter hospital stay and possibly lower costs are in favour of early intervention. Furthermore, older patients seem to benefit more from early invasive treatment.

\section{Acknowledgements Professional assistance in statistical analysis of Evelien Kolkman and Petra Koopmans from Diagram (Diagnostic Research And Management, Zwolle, The Netherlands) and Esther van't Riet (epidemiologist, Deventer Hospital, Deventer, The Netherland) was very much appreciated.}

Contributors All authors have contributed to the conception, design, analysis and interpretation of the data, revising of the drafts and have approved the final version of the manuscript.

Competing interests None declared.

Provenance and peer review Not commissioned; externally peer reviewed.

Open Access This is an Open Access article distributed in accordance with the Creative Commons Attribution Non Commercial (CC BY-NC 4.0) license, which permits others to distribute, remix, adapt, build upon this work non-commercially, and license their derivative works on different terms, provided the original work is properly cited and the use is non-commercial. See: http://creativecommons.org/ licenses/by-nc/4.0 (c) Article author(s) (or their employer(s) unless otherwise stated in the text of the article) 2017. All rights reserved. No commercial use is permitted unless otherwise expressly granted.

\section{REFERENCES}

1. Navarese EP, De Servi S, Gibson CM, et al. Early vs. delayed invasive strategy in patients with acute coronary syndromes without ST-segment elevation: a meta-analysis of randomised studies. QJM 2011;104:193-200.

2. Katritsis DG, Siontis GC, Kastrati A, et al. Optimal timing of coronary angiography and potential intervention in non-ST-elevation acute coronary syndromes. Eur Heart J 2011;32:32-40.

3. Rajpurohit N, Garg N, Garg R, et al. Early versus delayed percutaneous coronary intervention for patients with non-ST segment elevation acute coronary syndrome: a meta-analysis of randomised controlled clinical trials. Catheter Cardiovasc Interv 2013;81:223-31.

4. Milasinovic D, Milosevic A, Marinkovic J, et al. Timing of invasive strategy in NSTE-ACS patients and effect on clinical outcomes: a systematic review and meta-analysis of randomised controlled trials. Atherosclerosis 2015;241:48-54.

5. Bonello L, Laine M, Puymirat E, et al. Timing of coronary invasive strategy in Non-ST-segment elevation acute coronary syndromes and Clinical Outcomes: an updated meta-analysis. JACC Cardiovasc Interv 2016;9:2267-76.

6. Roffi M, Patrono C, Collet JP, et al. 2015 ESC guidelines for the management of acute coronary syndromes in patients presenting without persistent ST-segment elevation. Eur Heart $J$ 2016;37:267-315.

7. Badings $\mathrm{EA}$, The $\mathrm{SH}$, Dambrink JH, et al. Early or late intervention in high-risk non-ST-elevation acute coronary syndromes: results of the ELISA-3 trial. Eurolntervention 2013;9:54-61.

8. Reuter PG, Rouchy C, Cattan S, et al. Early invasive strategy in highrisk acute coronary syndrome without ST-segment elevation. the sisca randomised trial. Int J Cardiol 2015;182:414-8.

9. Oosterwerff EF, Fagel ND, Slagboom T, et al. Impact of percutaneous coronary intervention timing on 5-year outcome in patients with nonST-segment elevation acute coronary syndromes. the 'wait a day' approach might be safer. Neth Heart J 2016;24:173-80.

10. Damman P, van Geloven N, Wallentin L, et al. Timing of angiography with a routine invasive strategy and Long-Term outcomes in NonST-Segment elevation acute coronary syndrome. JACC CardiovasC Interv 2012;5:191-9.

11. Milosevic A, Vasiljevic-Pokrajcic Z, Milasinovic D, et al. Immediate versus delayed invasive intervention for Non-ST-Segment elevation myocardial infarction patients the RIDDLE-NSTEMI study. J Am Coll Cardiol Intv 2016;9:541-9.

12. Montalescot G, Cayla G, Collet JP, et al; ABOARD Investigators. Immediate vs delayed intervention for acute coronary syndromes: a randomised clinical trial. JAMA 2009;302:947-54.

13. Mehta SR, Granger CB, Boden WE, et al; TIMACS Investigators. Early versus delayed invasive intervention in acute coronary syndromes. N Engl J Med 2009;360:2165-75.

14. Thiele H, Rach J, Klein N, et al; LIPSIA-NSTEMI Trial Group. Optimal timing of invasive angiography in stable non-ST-elevation myocardial 
infarction: the leipzig immediate versus early and late PercutaneouS coronary intervention triAl in NSTEMI (LIPSIA-NSTEMI trial). Eur Heart $J$ 2012;33:2035-43.

15. Alexander KP, Newby LK, Cannon CP, et al; American Heart Association Council on Clinical CardiologySociety of Geriatric Cardiology. Acute coronary care in the elderly, part I: non-stsegment-elevation acute coronary syndromes: a scientific statement for healthcare professionals from the american heart association council on clinical cardiology: in collaboration with the society of geriatric cardiology. Circulation 2007;115:2549-69.

16. Bach RG, Cannon CP, Weintraub WS, et al. The effect of routine, early invasive management on outcome for elderly patients with non-
ST-segment elevation acute coronary syndromes. Ann Intern Med 2004;141:186-95.

17. Savonitto S, Cavallini C, Petronio AS, et al; Italian Elderly ACS Trial Investigators. Early aggressive versus initially conservative treatment in elderly patients with non-ST-segment elevation acute coronary syndrome: a randomised controlled trial. JACC Cardiovasc Interv 2012;5:906-16.

18. Tegn N, Abdelnoor M, Aaberge L, et al; After Eighty study investigators. Invasive versus conservative strategy in patients aged 80 years or older with non-ST-elevation myocardial infarction or unstable angina pectoris (After eighty study): an open-label randomised controlled trial. Lancet 2016;387:1057-65. 